\section{Pesticides and microorganisms}

Pesticide Microbiology: Microbiological Aspects of Pesticide Behaviour in the Environment. Edited by I. R. Hill and S. J. L. Wright. Pp. 844. (Academic: London, New York and San Francisco, 1978.) £38; $\$ 78.65$.

'SAFETY' is the current climate and there are stringent conditions governing the registration of pesticides, which are by their nature, biologically very active. These include microbiological investigations. This book is an attempt, and a very successful one, to bring together much of the literature on the reactions that take place between microorganisms (bacteria, fungi, microalgae and microfauna) in the various habitats (soil, air, water, plants and animals) in which they are found, and the various pesticides (insecticides, herbicides, fungicides and soil fumigants) which are used in agriculture and public health. This is a field (as indeed are all pesticide investigations) in which academic and industrial scientists meet on common ground with much benefit to both and this happy cooperation (which your reviewer has experienced) is reflected in the make-up of this book. One of the authors (I. R. Hill) is from ICl and

\section{EARTHQUAKES \\ Cause, Prediction, and Control}

\section{J. H. Tatsch}

We are pleased to report that this book is selling well in all parts of the world. The phenomenal demand for Earthquakes arises primarily from the fact that it explains how to determine where (and where not) to place nuclear power plants in order to minimize the possibility of earthquake damage.

The book is available directly from the address shown below or through book dealers in all parts of the world. Hard cover, $6 \times 9$ inches, 451 pages. Table of contents, line drawings, index, maps, references. $\$ 108$. ISBN: 0-912890-02-9. LC: $75-9305$ 1977.

Send for details.

Tatsch Associates,

120 Thunder Road,

Sudbury

Massachusetts,

01776, U.S.A.

Circle No. 14 on Reader Enquiry Card. the other (S. J. L. Wright) from the University of Bath. Their interests are reflected in the choice of authors-five from industry, five from universities, and three from research institutes. The result is a happy blending of fundamental and applied aspects.

The editors have done a splendid job in bringing together specialists from the various fields, and although they have obviously had difficulty in persuading all of them to meet publishing deadlines (a common hazard!) the finished products are works of real scholarship. Pesticide microbiology has really come of age academically and this volume (in the various editions that will surely follow) should be the standard text for workers in the field for many years to come. One of the most pleasing features of the book, at least to this reviewer, is that each chapter finishes with a set of "Con-

\section{Processes of osmoregulation}

Mechanisms of Osmoregulation in Animals: Maintenance of Cell Volume. Edited by R. Gilles. Pp. 667. (Wiley: Chichester, UK, and New York, 1979.) $£ 30$.

ONE of the vital activities of animals, and ultimately of cells, is an ability to regulate their water and solute content. This process, which results in the maintenance of the osmotic pressure and volume of cells, can take place in the face of a wide variety of environmental conditions which may be associated with many modifications in morphology and physiology. The occupation by animals of such contrasting habitats as the oceans, lakes of freshwater and hot arid deserts is only made possible as a result of such adaptations. Claude Bernard more than 100 years ago elevated the study of this subject to one suitable for intellectual reflection and he also, to use a modern idiom, made it 'relevant'. Osmoregulation has since attracted people from many disciplines including biology, medicine, and even the physical and environmental sciences.

For this book Dr Gilles has assembled a group of authors which reflects this widespread interest in osmoregulation and provides the reader with an excellent opportunity to benefit from the expertise of each. The survey is broad in its design, including both vertebrates and invertebrates and it ranges from basic physicochemical principles, as applied to cells, to the nature of some pathological disorders of fluid regulation in man. I found the basic mechanisms of osmoregulation to be especially well described throughout the book and clusions". There are so many investigations using such a variety of techniques that the reader is in danger of becoming bewildered and lost in a mass of data. But don't expect the conclusions to be conclusive. The environment is too variable a medium for that, but a little drawing together of information is welcome.

This is essentially a book for the research worker, and in this respect one might question the value of chapters one and two, which are introductory in nature. Although both chapters are well written their exclusion would have thinned the book a little and might have reduced the rather frightening price of $£ 38$.

W. W. Fletcher

W. W. Fletcher is Professor of Biology at the University of Strathclyde, Glasgow, $U K$.

this should provide a very useful basis for teaching students. A comparative survey of osmoregulation among the vertebrates has been provided, which is well presented; but presumably because of limitations on the size of the book it is not a complete one. Apart from their kidneys, mammals have been relatively neglected and some interesting and exotic groups such as the cyclostome fishes and lungfishes get little attention. The roles and mechanisms of action of hormones in osmoregulation of vertebrates have been admirably described. However, the interesting effects of prolactin, which helps regulate the secretion of milk in mammals but osmoregulation in some fishes, possibly merits more attention.

The contributions are up to date and include full references up to 1976 with some as recent as 1978 . The text is clearly set out so that it is easy to find and select topics of interest. I enjoyed reading this book and have no hesitation in recommending it to graduate students and research scientists who are interested in this subject. It will be especially useful to those who are searching for a clear summary of background material on which to build a sound knowledge of the processes of osmoregulation. This volume also contains much of general interest for students in zoology and physiology. The price suggests that the book is mainly directed towards libraries so that unfortunately its accessibility to students may be limited. Possibly the publishers should consider a paperback edition for the impecunious?

Peter J. Bentley

Peter J. Bentley is Professor of Pharmacology at the Mount Sinai School of Medicine, Mount Sinai Hospital, New York. 